\title{
DEVELOPMENT OF HIGH-VANADIUM ALLOY FOR PLASMA-POWDER SURFACING OF KNIVES FOR CUTTING OF NON-METALLIC MATERIALS
}

\author{
E.F. PEREPLYOTCHIKOV \\ E.O. Paton Electric Welding Institute, NASU \\ 11 Bozhenko Str., 03680, Kiev, Ukraine. E-mail: office@paton.kiev.ua
}

\begin{abstract}
The results of investigations of structure, hardness and wear resistance of iron-based alloys containing up to $4.5 \% \mathrm{C}$ and $15 \% \mathrm{~V}$ are given. The dependence of structure and type of carbides on chemical composition of these alloys was studied. The analysis of effect of structure on wear resistance at abrasive wear of deposited metal, close by its composition to the investigated alloys, in initial state and after heat treatment was made. It was established that deposited metal of this type has a high wear resistance due to formation of martensite structure with small amount of residual austenite and with disperse, uniformly distributed carbides of vanadium and carbides of $\mathrm{Me}_{23} \mathrm{C}_{6}$ type. 6 Ref., 1 Table, 3 Figures.
\end{abstract}

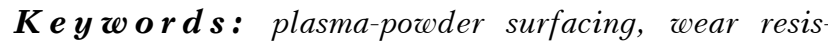
tance, dilatometric analysis, powders for surfacing, highvanadium alloys

At the present time for saving of expensive tool steels in manufacture of different tools, including knives for cold and hot cutting of different materials, surfacing is very widely applied. In this case the body of a tool is manufactured of relatively chip structural steel and its working edges or working surfaces are manufactured of a tool steel.

The basic alloying elements for tool steels and alloys are tungsten, molybdenum and chromium, which form comparatively coarse (up to $50 \mu \mathrm{m}$ ) carbides during surfacing, thus leading to crumbling of working edges of knives. Due to this reason thin-blade tool is manufactured either of highly-deformed steels, carbide net of which was fractured in the process of forging and rolling, or of powder tool steels, the technology of production of which excludes the possibility of formation of coarse-grain structures and carbide heterogeneity. In this connection, when selecting the system for deposited metal alloying, the preference is given to vanadium, which forms very tiny and solid carbides [1-3]. The obstacle for application of vanadium as an alloying element in electrode and filler materials for arc surfacing is its capability to form spinels, which complicates the removal of slag crust. Due to this reason the mass fraction of vanadium in flux-cored wires for arc surfacing of tool steels is restricted to $0.5 \%$ [2]. The wider capabilities for alloying the deposited metal with vanadium are opened in using plasma-powder surfacing (PPS) in inert shielding gases.

(C) E.F. PEREPLYOTCHIKOV, 2014
To create the principally new class of surfacing materials for knives of cold cutting of non-metallic materials the alloys based on iron in the form of powders with calculated mass fracture of vanadium of up to $20 \%$ and carbon up to $4.5 \%$ were investigated. The powders for surfacing were manufactured by spraying of liquid melt using nitrogen.

It is very important for tool steels to select the optimal ratio of concentrations of carbon and carbide-forming elements. Depending on the stoichiometric composition of the forming carbides for each percent of vanadium in steel 0.175 $\left(\mathrm{V}_{4} \mathrm{C}_{3}\right), 0.196\left(\mathrm{~V}_{6} \mathrm{C}_{5}\right)$ or $0.236 \% \mathrm{C}(\mathrm{VC})$ is required. To provide the best combination of properties of alloy it is desirable that the ratio of vanadium to carbon in it was within the limits of 3.5-4.0 [4]. At the presence of other carbideforming elements in steel the content of carbon should be sufficient to form the appropriate carbides and strengthening of matrix. Taking this into consideration the alloys were selected for investigations, the chemical composition of which is given in the Table.

Except of participation in carbides formation the chromium and molybdenum impart the tendency of alloys to hardening and provide obtaining of martensite base. Chromium at the content of about $15 \%$ should also provide anticorrosion properties of alloys.

Alloys 4 and 5 were alloyed using nickel. It was expected that it would result in formation of austenite in their structure. Moreover, alloy 5 was alloyed using niobium, thus providing the possibility to carry out evaluation of properties of alloy in use of one more strong carbide-former. 
Chemical composition, hardness and wear of investigated iron-based high-carbon high-vanadium alloys

\begin{tabular}{|c|c|c|c|c|c|c|c|c|c|}
\hline \multirow{2}{*}{$\begin{array}{l}\text { Number of } \\
\text { alloy }\end{array}$} & \multicolumn{7}{|c|}{ Mass fraction of elements, \% } & \multirow{2}{*}{$\begin{array}{c}\text { Hardness } \\
H R C\end{array}$} & \multirow{2}{*}{$\begin{array}{c}\text { Loss of mass, } \\
\text { mg }\end{array}$} \\
\hline & $\mathrm{C}$ & Mn & $\mathrm{Si}$ & $\mathrm{Cr}$ & $\mathrm{V}$ & Mo & $\mathrm{Ni}$ & & \\
\hline 1 & 3.95 & 0.91 & 1.07 & 16.76 & 14.15 & 2.03 & - & $45-48$ & 12.30 \\
\hline 2 & 4.25 & 1.76 & 1.43 & 16.72 & 15.18 & 1.97 & - & $50-54$ & 5.05 \\
\hline 3 & 4.38 & 1.11 & 1.05 & 16.65 & 14.62 & 2.01 & - & $60-62$ & 4.40 \\
\hline 4 & 4.45 & 1.01 & 0.64 & 16.03 & 14.66 & 2.00 & 1.08 & $60-62$ & 4.60 \\
\hline $5^{*}$ & 4.68 & 1.00 & 0.80 & 14.15 & 14.91 & 2.10 & 1.30 & $55-59$ & 5.42 \\
\hline
\end{tabular}

Considering the fact that pilot alloys were supposed to be used for manufacture of bimetallic knives of different purpose, the hardness, wear resistance and structure of deposited metal with chemical composition, corresponding to the pilot alloys, were investigated.

Initially the investigation of welding and technological properties of high-carbon high-vanadium alloys was carried out. The surfacing was carried out using plasma-powder method, as the base metal the plates of steel St3 were used. Edge preparation for surfacing was made in them, the sizes of which corresponded to the sizes on the real tool for cutting of non-metallic materials. The most important parameters of PPS are the arc current $I_{\mathrm{a}}$, speed of surfacing $v_{\mathrm{s}}$ and rate of powder feed [5]. In the experiments $I_{\mathrm{a}}=140$ $280 \mathrm{~A}$ and $v_{\mathrm{s}}=2.0-5.3 \mathrm{~m} / \mathrm{h}$ were used. In the investigated range of condition parameters fraction of base metal in the deposited metal is varied from 0 to $25 \%$. In the region of low values of current the increase by $10 \mathrm{~A}$ results in increase of fraction of base metal in the deposited metal by $2-5 \%$.

In general the composition of deposited metal is differed from the composition of filler (electrode) metal due to its stirring with the base metal and also oxidation or selective evaporation of alloying elements [6]. In PPS according to the optimal modes the fraction of base metal in the deposited layer does not exceed 5-8\%, weld pool is reliably protected from oxidation by argon, and there are no easily-evaporating elements in the composition of investigated alloys. In connection with that the composition of deposited metal almost corresponds to the composition of powder [5].

The optimal $I_{\mathrm{a}}$ values at different deposition rates provide a good formation and constant width and height of beads. Though PPS using high-carbon high-vanadium alloys was carried out without preheating, there was not noticed a single case of crack and pore formation in the deposited metal.
For evaluation of wear resistance of high-vanadium alloys the methods of tests for wear using fixed abrasive were selected. As an abrasive the corundum skin with grain size of $180 \mu \mathrm{m}$ was used, the area of friction amounted to $1 \mathrm{~cm}^{2}$, pressure was $30 \mathrm{~N}$, test time was $20 \mathrm{~s}$. Evaluation of wear resistance was carried out according to the loss of mass of tested specimens.

The specimens for metallographic tests were cut out of deposited metal and subjected to etching in the Murakami reagent.

The specimens of the size $3 \times 3 \times 25 \mathrm{~mm}$ for dilatometric investigations were manufactured of metal deposited by powders of selected alloys using plasma method. In the Shevenar dilatometer the specimens were heated at the rate of $2.5{ }^{\circ} \mathrm{C} / \mathrm{min}$ to 430,630 and $1045{ }^{\circ} \mathrm{C}$, subjected to holding for $2 \mathrm{~h}$ at these temperatures and then cooled at the rate of $40{ }^{\circ} \mathrm{C} / \mathrm{min}$. In quick-response dilatometer during simulation of thermal cycle of surfacing the specimens were heated to $1150{ }^{\circ} \mathrm{C}$ at the rate of $130{ }^{\circ} \mathrm{C} / \mathrm{s}$ and cooled at the rate of $7.5^{\circ} \mathrm{C} / \mathrm{s}$ without the holding.

In the Table the results of tests on wear resistance of alloys deposited at the optimal modes are also presented. It should be noted for comparison that in the widely known tool steel R6M5F2 tested under the same conditions, the loss of mass amounted to 19.2 and in the solid alloy of the VK8 type - $1.6 \mathrm{mg}$. As is seen from the given data, high-carbon high-vanadium alloys occupy as to the wear resistance an intermediate position between tool steels and solid alloys but they are considerably cheaper than the latter ones.

It was found, that alloys 1 and 2 have the lowest hardness (HRC 45-54). In the process of tempering at $600{ }^{\circ} \mathrm{C}$ during $1 \mathrm{~h}$ it is increased to $H R C 59$, obviously, due to precipitation of carbides and decay of residual austenite with formation of martensite. Alloys 3 and 4 have the maximum hardness after surfacing ( $H R C$ 6062). After tempering at up to $550{ }^{\circ} \mathrm{C}$ the hardness of these alloys is almost retained at the initial 

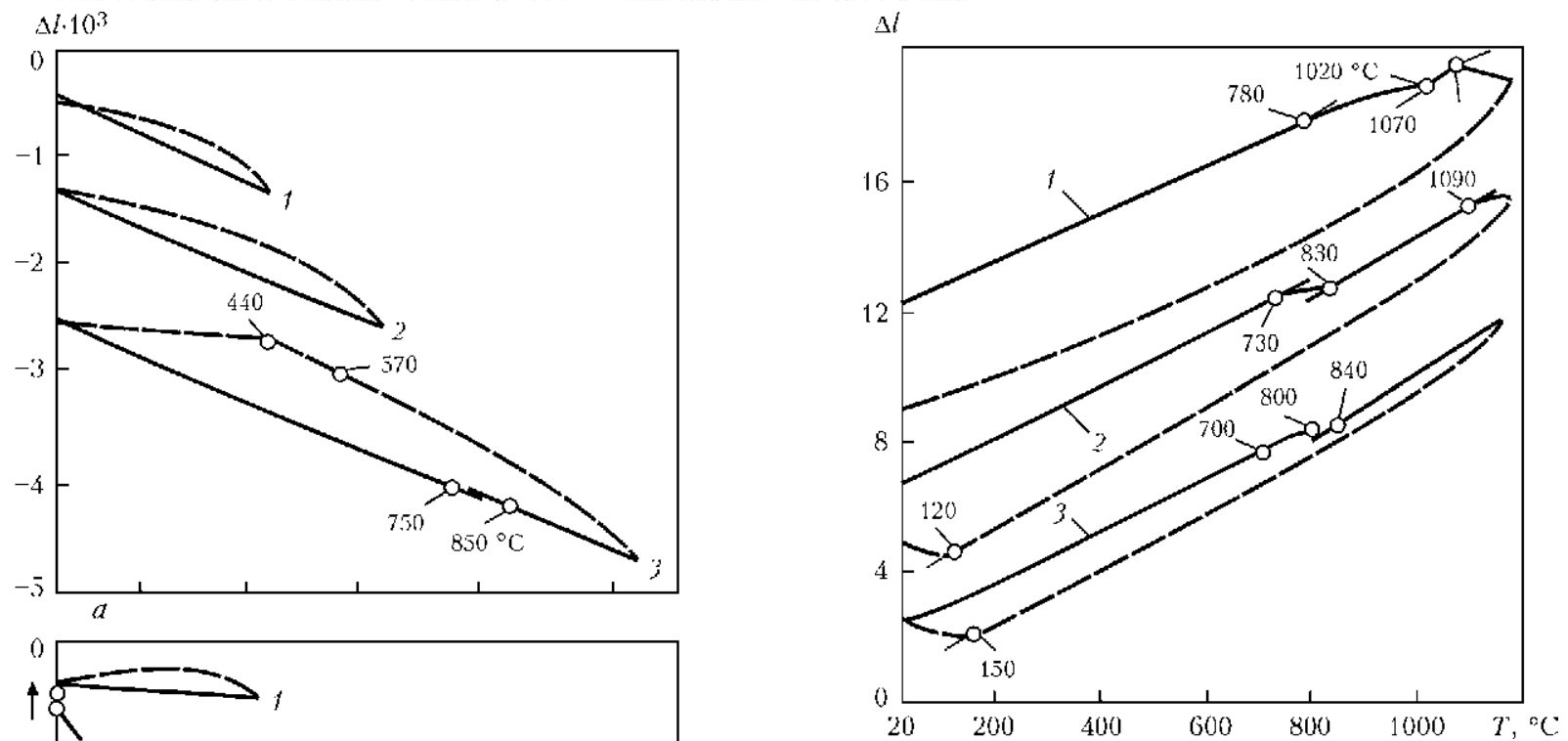

Figure 2. Curves of heating (solid lines) and cooling (dash) of alloys $1,3,5(1-3)$ in quick-response dilatometer

clined downwards and fully convertible. The increase in temperature of tempering to $630{ }^{\circ} \mathrm{C}$ results in a small decrease in length of specimen in the process of 2-hour holding, which is connected with precipitation of carbides. During cooling the residual austenite is transformed into martensite $\left(\mathrm{M}_{\mathrm{s}}=200-220{ }^{\circ} \mathrm{C}\right)$. Martensite transformation is continued in both alloys during holding at room temperature (see arrows in Figure 1, $b, c)$. The character of curves of heating to $1045^{\circ} \mathrm{C}$ and cooling from this temperature for alloys 3 and 5 is almost the same. In the range of temperatures $790-1000{ }^{\circ} \mathrm{C}$ (alloy 3 ) and $830-$ $1020{ }^{\circ} \mathrm{C}$ (alloy 5) the structure of alloys is relatively stable. When temperatures are higher the dissolution of carbides in austenite occurs and this process is running with increase in length. During cooling of specimens from $1045{ }^{\circ} \mathrm{C}$ martensite transformation $\left(\mathrm{M}_{\mathrm{s}}=160{ }^{\circ} \mathrm{C}\right)$ occurs in both alloys, which is continued in the process of holding at room temperature, the same as at lower temperatures. The inclination of curves for specimens 3 and 5 corresponds to the mixed $\alpha+$ $+\gamma$-structure. In these alloys the nature of $\alpha$-phase is martensite, the structure of matrix is composed of mixture of martensite and residual austenite.

Figure 2 shows dilatometric curves of heating and cooling of alloys 1, 3 and 5 obtained in quickresponse dilatometer at simulation of thermal cycle of surfacing. In specimen 1 during heating in the range of $670-880{ }^{\circ} \mathrm{C}$ small increase in length occurs, possibly, connected with dissolution of carbides. In cooling the monotonous decrease in length without any transformations takes place. At the curve of heating of specimen 3 the inflection at $730-830{ }^{\circ} \mathrm{C}$ was noted connected with $\alpha+\gamma$-transformation. In the process of cooling heating to $430{ }^{\circ} \mathrm{C}$ of both alloys are slightly in- 


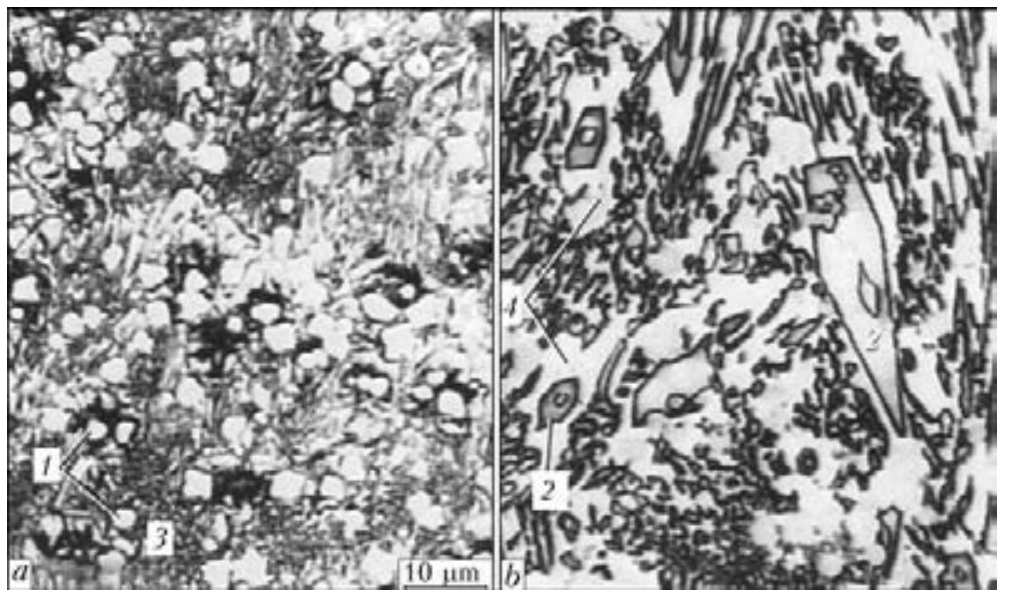

Figure 3. Microstructure $(\times 1000)$ of high-carbon high-vanadium alloys $2(a)$ and $3(b): 1-$ vanadium carbide; $2-$ $\mathrm{Me}_{7} \mathrm{C}_{3}$ carbide; 3 - martensite-austenite structure with domination of martensite; 4 - martensite-austenite structure with domination of austenite

the martensite transformation $\left(\mathrm{M}_{\mathrm{s}}=120{ }^{\circ} \mathrm{C}\right)$ is observed. The curve of alloy 5 has the similar character: $\alpha+\gamma$-transformation occurs at 700$840{ }^{\circ} \mathrm{C}, \mathrm{M}_{\mathrm{s}}=150{ }^{\circ} \mathrm{C}$. Obviously, the process of carbides precipitation influences the $\alpha+\gamma$-transformation in both cases. The $\mathrm{M}_{\mathrm{s}}$ points obtained in two types of dilatometers are somewhat differed from each other, which is possibly connected with deviations in chemical composition of specimens of the deposited metal and also peculiarities of methods of investigations in these dilatometers.

Investigations in quick-response dilatometer show that at thermal cycle of plasma surfacing without additional heat treatment of high-vanadium high-carbon alloys can acquire the most favorable martensite-carbide structure with a small amount of residual austenite, from the point of view of wear resistance. The direct investigations of microstructure proved the conclusions of dilatometric investigations that the matrix of alloy 3 has martensite structure with some amount of residual austenite. Carbides of vanadium of the $\mathrm{MeC}$ type and chromium carbides of the $\mathrm{Me}_{23} \mathrm{C}_{6}$ type are uniformly distributed in the structure of alloy and their size does not exceed $10 \mu \mathrm{m}$ (Figure 3, a). Alloy 5 has also martensite-austenite structure but, as a result of increased carbon content in it, large acicular chromium carbides of the type $\mathrm{Me}_{7} \mathrm{C}_{3}$ are formed, except of carbides of vanadium and niobium of the type MeC (Figure 3, b). Measurements of microhardness ( $H V 0.05)$ of structure components of the investigated alloys showed that hardness of carbides of the type $\mathrm{MeC}$ amounts to 2900-3000, carbides of the type $\mathrm{Me}_{7} \mathrm{C}_{3}-900-$ 1300, martensite $-800-900$, austenite $-600-$ 700 , and ferrite has hardness of $H V 0.05=550-600$.
Alloys 3 and 5 showed almost the same wear resistance at abrasive wear, however in alloy 5 chromium carbides have considerable sizes, therefore, alloy 3 will be more preferable for surfacing of knives.

\section{Conclusions}

1. It was established that depending on chemical composition the matrix of high-carbon high-vanadium alloys can be composed of combination of different structure components: martensite, austenite or alloyed ferrite. Besides, in the structure of alloys the considerable amount of carbides of basic alloying elements, such as vanadium and chromium, is contained. The highest wear resistance at abrasive wear is provided by martensitecarbide structure with small amount of residual austenite.

2. Thermal cycle of plasma surfacing without additional heat treatment provides obtaining the most favorable martensite-carbide structure with small amount of residual austenite in high-vanadium high-carbon deposited metal, from the point of view of wear resistance.

1. Goudremont, E. (1966) Special steels. Vol. 2. Moscow: Metallurgiya.

2. Efimov, Yu.V., Baron, V.V., Savitsky, E.M. (1969) Vanadium and its alloys. Moscow: Nauka.

3. Livshits, L.S., Grinberg, N.A., Kurkumelli, E.G. (1969) Principles of alloying of deposited metal. Moscow: Mashinostroenie.

4. Meskin, V.S. (1964) Principles of alloying of steel. Moscow: Metallurgiya.

5. Gladky, P.V., Pereplyotchikov, E.F., Ryabtsev, I.A. (2007) Plasma surfacing. Kiev: Ekotekhnologiya.

6. Ryabtsev, I.A., Kondratiev, I.A. (1999) Mechanized electric arc surfacing of metallurgical equipment parts. Kiev: Ekotekhnologiya. 